\title{
Lactate Dehydrogenase Isoenzyme 5 Measurement
}

National Cancer Institute

\section{Source}

National Cancer Institute. Lactate Dehydrogenase Isoenzyme 5 Measurement. NCI

Thesaurus. Code C74891.

The determination of the lactate dehydrogenase isoenzyme 5 present in a sample. 